were most probably made by predators. It should be recognized, however, that there is an intergradation between parasitism and predation that is usually not resolvable in the fossil record, and also that a mineralized shell is useful to hold off any attacking organism, whether parasite or predator.

Predator pressure may induce a variety of responsive strategies with great evolutionary potential for differentiation and speciation (10). With regard to shell-boring, the best investigated cases concern gastropod predation on bivalves. The main factors in prey selection appear to be the ratio between prey biomass and shell thickness, and the relative size of predator and prey (22). Responses by nonmotile prey would thus involve reduction in shell penetrability and modifications of ontogenetic growth $(26,27)$.

The low percentage of bored Cloudina is comparable to the generally low levels of shell-boring predation through the Palaeozoic, before the Mesozoic evolution of shell-boring gastropods $(10,24,28,29)$. The apparent predator on Cloudina selected its prey for size, as do shell-boring gastropods. Due to the secondarily phosphatized preservation of the Cloudina walls in our material, the original shell thickness is difficult to measure in specimens isolated from the rock. Thus there are currently no data indicating whether the predator also preferred individuals with a high ratio of biomass to shell thickness. Furthermore, as Cloudina is nowhere known to span a substantial stratigraphic interval and no evolutionary ancestors or descendants have been positively identified, there is currently no time frame available in which to study the possible evolutionary effects of early predation.

Nevertheless, the apparent predation on Cloudina is highly significant for our understanding of the dramatic biotic events around the Precambrian-Cambrian boundary. First, it would mean that the marine food web already extended to macrophagous predation in the late Precambrian ecosystems. Second, the occurrence of borings, in particular the unsuccessful ones, suggests that at least one function of the first mineralized skeletons was to thwart predators. Third, the possibility of active selection for size by this Precambrian predator indicates a level of neural complexity usually associated with bilaterian animals. Fourth, the evidence fits the prediction of those models of Precambrian-Cambrian evolution that affix a high significance to the appearance of carnivory (and herbivory) both for the origin of mineralized skeletons and for the general ecological diversification. Fifth, we have a possible way to obtain the data necessary for more rigorous testing of such hypotheses in the future.

\section{REFERENCES AND NOTES}

1. F. H. T. Rhodes and T. W. Bloxam. Proceedings of the North American Paleontological Convention (1971), vol. K, p. 1485.

2. E. T. Degens, Chem. Geol. 25, 257 (1979).

3. J. Kaźmierczak, V. Ittekott, E. T. Degens, Palaeontol. Z. 59, 15 (1985)

4. J. Kaźmierczak and E. Degens, Mitt. Geol.-Palaeontol. Inst. Univ. Hamburg 61, 1 (1986).

5. M. F. Glaessner, The Dawn of Animal Life. A Biohistorical Study (Cambridge Univ. Press, Cambridge, 1984), p. 244.

6. J. W. Valentine and D. H. Erwin, Mar. Biol. Lab. Lect. Biol. 8, 71 (1987).

7. J. W. Evans, Compte Rendu de la XI:e Session du Congrès Géologique International (Stockholm 1910), Premier Fascicule (1912), p. 542.

8. G. E. Hutchinson, in Oceanography, M. Sears, Ed. (AAAS, Washington, DC, 1967), p. 85.

9. S. Bengtson, Acta Univ. Ups. Abstr. Upps. Diss. Fac. Sci. 415, 71 (1977)

10. G. J. Vermeij, Evolution and Escalation. An Ecological History of Life (Princeton Univ. Press, Princeton, NJ, 1987).

11. G. J. Vermeij, Palaios 4, 585 (1990)

12. S. Conway Morris, Am. Sci. 75, 157 (1987).

13. J. W. Valentine, S. M. Awramik, P. W. Signor, P. M. Sadler, Evol. Biol. 25, 279 (1991).

14. S. M. Stanley, Proc. Natl. Acad. Sci. U.S.A. 70 , 1486 (1973).

15. Am. J. Sci. 276, 56 (1976).

16. G. J. B. Germs, Chamb. Mines Precambr. Res.
Unit Bull. 12, 250 (1972)

17. G. Hahn and H. D. Pflug, Senckenbergiana Lethaea 65, 413 (1985)

18. S. Conway Morris, B. W. Mattes, Chen Menge, Am. J. Sci. 290A, 245 (1990)

19. S. W. F. Grant, Am. J. Sci. 290(A), 261 (1990).

20. Chen Menge, Chen Xianggao, Lao Qiuyuan, Sci. Geol. Sinica 1975(2), 181 (1975).

21. Xing Yusheng et al., Bull. Inst. Geol. Chin. Acad. Geol. Sci. Spec. Issue 10 (1984).

22. J. A. Kitchell, C. H. Boggs, J. F. Kitchell, J. A Rice, Paleobiology 7, 533 (1981)

23. L. N. Popov, K. K. Khazanovich, N. G. Borovko, S P. Sergeeva, R. F. Sobolevskaya, Akad. Nauk SSSR, Min. Geol. SSSR, Mezhvedomstv. Stratigr. Komitet SSSR, Trudy 18 (1989)

24. A. R. Kabat, Malacologia 32, 155 (1990)

25. D. K. Young, Am. Zool. 9, 903 (1969).

26. J. A. Kitchell, 3rd North Am. Paleontol. Conv. Proc. 2, 301 (1982)

27. D. L. DeAngelis, J. A. Kitchell, W. M. Post, Am. Nat. 126, 817 (1985).

28. N. F. Sohl, Am. Zool. 9, 725 (1969).

29. S. Conway Morris and S. Bengtson, J. Paleontol. in press.

30. We are grateful to S. Conway Morris, S. W. Grant, B. Runnegar, P. W. Signor, III, and G. $\mathbb{R}$ Vermeij for constructive comments on the manuscript. Supported by the Swedish Natural Scienee Research Council and the National Natural Science Foundation of China.

12 March 1992; accepted 1 June 1992

\title{
Crystal Structure of Transforming Growth Factor-ß2: An Unusual Fold for the Superfamily
}

\author{
Sun Daopin, Karl A. Piez, Yasushi Ogawa, David R. Davies*
}

The transforming growth factors $\beta$ (TGF- $\beta 1$ through - $\beta 5$ ) are a family of homodimeris cytokines that regulate proliferation and function in many cell types. Family members have 66 to $80 \%$ sequence identity and nine strictly conserved cysteines. A crystal structure of member of this family, TGF- $\beta 2$, has been determined at 2.1 angstrom $(\AA)$ resolution an refined to an $\boldsymbol{R}$ factor of 0.172 . The monomer lacks a well-defined hydrophobic core an displays an unusual elongated nonglobular fold with dimensions of approximately $60 \AA$ b $20 \AA$ by $15 \AA$. Eight cysteines form four intrachain disulfide bonds, which are clustered i a core region forming a network complementary to the network of hydrogen bonds. The dim $\varnothing_{9}$ is stabilized by the ninth cysteine, which forms an interchain disulfide bond, and by twe identical hydrophobic interfaces. Sequence profile analysis of other members of the TGF- $\$$ superfamily, including the activins, inhibins, and several developmental factors, imply tha: they also adopt the TGF- $\beta$ fold.

The transforming growth factors- $\beta$ (TGFBs) are a family of multifunctional growth and differentiation factors that act on most cell types with activities dependent upon the cell type, stage of proliferation, and environment [for reviews, see (1-5)]. Of particular interest are their abilities to stimulate connective tissue synthesis, to suppress proliferation and function of immune cells, to inhibit proliferation of endothelial

S. Daopin and D. R. Davies, Laboratory of Molecular Biology, National Institute of Diabetes, Digestive and Kidney Diseases, National Institutes of Health, Bethesda, MD 20892

K. A. Piez, Fogarty International Center, National Institutes of Health, Bethesda, MD 20892.

Y. Ogawa, Celtrix Pharmaceuticals, Inc., 3055 Patrick Henry Drive, Santa Clara, CA 95052

*To whom correspondence should be addressed. and other epithelial cells, to stimulate osteogenic activity, and to be chemotactic for monocytes and fibroblasts. Five isoforms that have similar but not identical activities (TGF- $\beta 1$ to $-\beta 5$ ) have been discovered and have 66 to $80 \%$ sequence identity (6-17).

A larger group of proteins, referred to as the TGF- $\beta$ superfamily, have $-30 \%$ sequence identity to TGF- $\beta 1$ and seven invariant cysteines [see (2)]. They include the activins and inhibins, Mullerian inhibiting substance (MIS), the bone morphogenetic proteins (BMPs), the decapentaplegic (DPP-C) gene complex of Drosophila, and the closely homologous $V g I$ and $V g r-1$ genes of Xenopus and mouse, respectively.

The TGF- $\beta$ s are homodimers with molecular masses of $\sim 25,000$ daltons. Each 
subunit consists of 112 amino acids, except TGF- $\beta 4$, which has 114 . Heterodimers, designated TGF- $\beta 1.2$ and TGF- $\beta 2.3$, are also known to exist in small amounts in certain tissues $(18,19)$. Each polypeptide chain has nine disulfide-bonded cysteines, which are invariant among the five forms (19). The TGF- $\beta$ s are synthesized in precursor forms of $\sim 400$ residues per chain and are secreted as latent complexes, which are activated later by proteolytic processing and

dissociation of the latent forms.

We report the three-dimensional (3-D) structure of the mature form of human TGF- $\beta 2$ determined by $\mathbf{x}$-ray crystallography at $2.1 \AA$ resolution. Sequence comparisons among the members of the superfamily were made by using a profile $(20,21)$ based on the local environment of the residues in TGF- $\beta 2$ that enables us to draw conclusions about the putative structures of the other members.

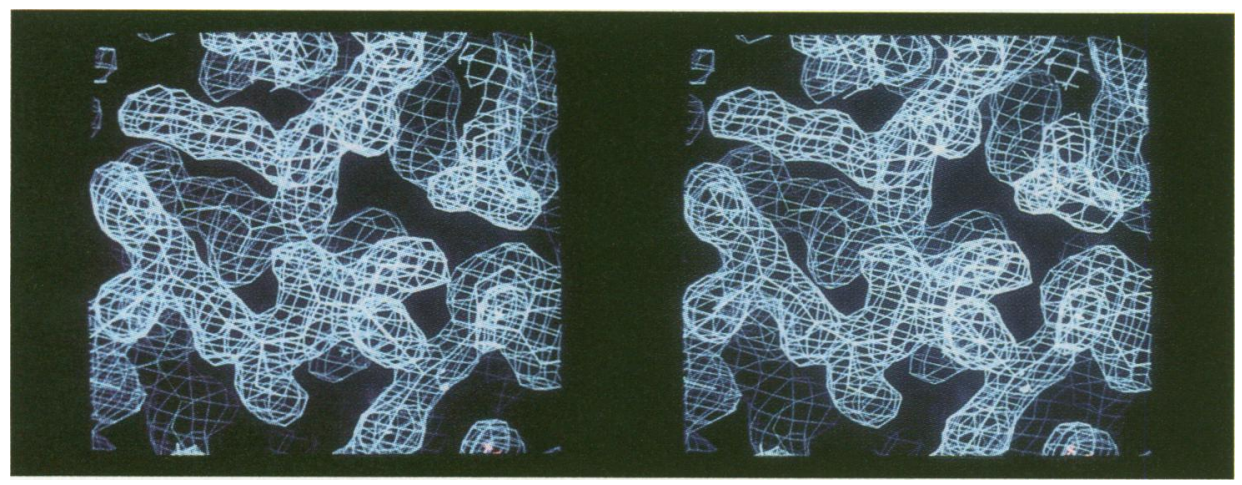

Fig. 1. Stereo pair showing a representative region around $\operatorname{Trp}^{52}, \mathrm{Ser}^{53}, \mathrm{Ser}^{54}, \mathrm{Asp}^{55}$, and Lys ${ }^{110}$ of the refined $\left(2 F_{\mathrm{o}}-F_{\mathrm{c}}\right)$ electron density map contoured at a level corresponding to one $\sigma$ (standard deviation of the map).

Fig. 2. (A) Topology diagram of a TGF- $\beta 2$ subunit. The $\alpha$ helices are labeled as $\alpha 1, \alpha 2$, and $\alpha 3$ and peptide strands in $\beta$ sheets are labeled from $\beta 1$ through $\beta 9$. The residues involved in the regular secondary structure are: $\alpha 1$, residues 4 to $8 ; \alpha 2$, 24 to $28 ; \alpha 3,58$ to $68 ; \beta 1,15$ to $18 ; \beta 2,20$ to $23 ; \beta 3,37$ to $40 ; \beta 4,42$ to $46 ; \beta 5,77$ to $80 ; \beta 6,82$ to $91 ; \beta 7,96$ to $102 ; \beta 8,104$ to 106 ; and $\beta 9$, 109 to 112 . (B) Schematic drawing of the primary and secondary structure of a TGF- $\beta 2$ subunit. Hydrogen bonds in the $\beta$ strands and loops are indicated by dashed lines. The analogy to a left hand can be seen. The heel (helix $\alpha 3$ ) is to the right and the fingers ( $\beta$ strands) are to the left with the third and fourth fingers twisted.
A

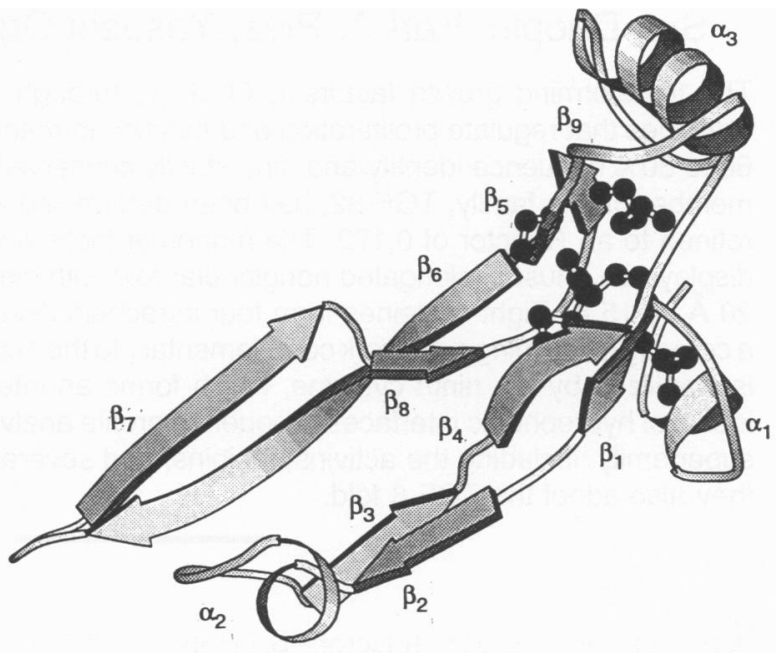

B

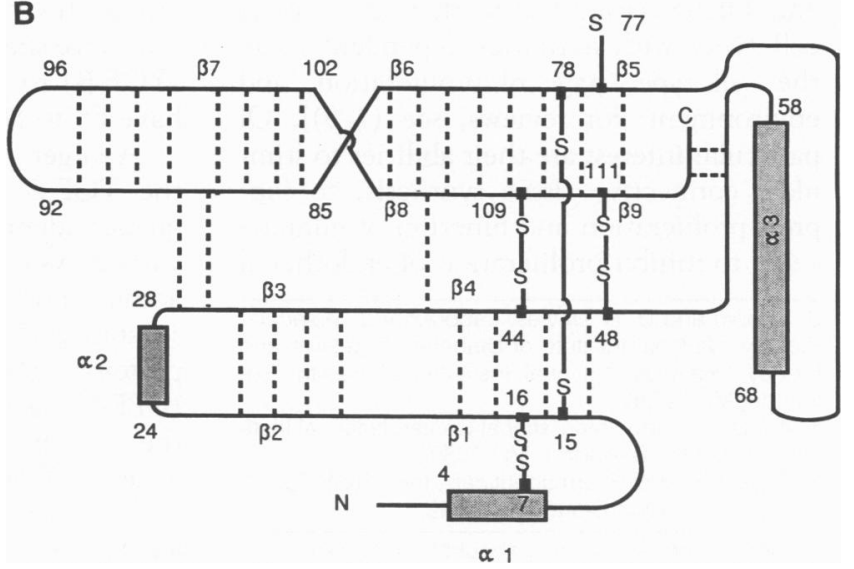

The structure determination is described in Table 1. A typical section of the electron density map $\left(2 F_{o}-F_{c}\right)$ with refined phases is shown in Fig. 1. The 112-amino acid subunit of TGF- $\beta 2$ displays a very unusual fold (Figs. 2 and 3 ). The secondary structure consists largely of short, two-stranded antiparallel $\boldsymbol{\beta}$ sheets, the longest of which extends from residue 82 to 91 and 96 to 105 , in agreement with the secondary structure assignments of TGF- $\beta 1$ from nuclear magnetic resonance (NMR) data (22). There are three $\alpha$ helices in the structure: helix $\alpha 1$, residues 4 to 7 ; helix $\alpha 2$, residues 24 to 28 , which consist of one turn only; and helix $\alpha 3$, residues 58 to 68 , which is longer. All three helices have also been observed in TGF- $\beta 1$ by NMR (22). Of the seven Pro residues, only Pro ${ }^{36}$ adopts the cis peptide configuration. The Ramachandran plot shows no residues in forbidden regions

The 112-residue subunit has the overalbo shape of a slightly curled left hand withfingers, formed by $\beta$ strands and loops, extended in pairs (Figs. 2 and 3). The three-turn helix $\alpha 3$ forms the heel of the hand. The amino- and carboxyl-terminalO ends are in the same region and are helde tightly to the body of the hand; the ten amino-terminal residues form the thumb of the hand. The loop at the end of the mosto extended pair of fingers, corresponding to residues 91 to 96 , is poorly defined in the electron density map. The dimensions of the subunit are approximately $60 \AA$ by $20 \AA \frac{\Phi}{\mathcal{O}}$ by $15 \AA$. There is no defined hydrophobic? core in the subunit as a result of the extended shape of the molecule, suggesting that the only stable form of the molecule in solution is a dimer.

The strictly conserved nine cysteines ing the sequence of the TGF- $\beta$ s suggest and important role in structure and function. InO the crystal structure, all nine cysteines form disulfide bonds. Eight form four intrachaino disulfide bonds between residues 7 and 16, 15 and 78, 44 and 109, and 48 and 111; one participates in an interchain disulfide bond between residue 77 of one monomer and residue 77 of the other. The four intrachain disulfides form a core (Fig. 3) that is essentially inaccessible to solvent and have very low crystallographic $B$ factors. The accessible side chain (C $\beta-S-S-C \beta$ ) areas of the four disulfides $(7-16,15-78,44-109$, and 48-111), measured in the dimer, are 0.1 , $1.9,2.4$, and $0.8 \AA^{2}(23)$, respectively, and the averaged side chain $B$ factors are 20.1 , $17.2,18.4$, and $17.2 \AA^{2}$, respectively. In contrast, the interchain disulfide is much more exposed and has greater mobility. Its side chain solvent accessible area is $58 \AA^{2}$, and the averaged side chain $B$ factor is 27 $\AA^{2}$. Consistent with this result, chemical studies have shown that the two subunits can be separated by mild reduction (18). 
Additional discussion of disulfide bonding appears below in the context of the superfamily.

The two chains of the dimer are related by a twofold axis going through the middle of the 77-77 disulfide bond (Fig. 4). The interface is made largely of hydrophobic residues. The twofold symmetry results in two identical hydrophobic cores on either side of the interchain disulfide. Helix $\alpha 3$ in one subunit (the heel of the hand) lies against the curved $\beta$-sheet area of the other subunit, involving strands $\beta 6, \beta 7$, and $\beta 8$ (third and fourth fingers of the hand), parts of strands $\beta 2$ and $\beta 3$, and the long loop between $\beta 2$ and $\beta 3$ (first and second fingers of the hand). The hydrophobic residues involved in this core packing are $\mathrm{Val}^{61}$, $\mathrm{Leu}^{62}, \mathrm{Leu}^{64}, \mathrm{Tyr}^{65}$, and $\mathrm{Ile}^{68}$ of helix $\alpha^{3}$ and $\mathrm{Ile}^{22}, \mathrm{Phe}^{24}, \mathrm{Leu}^{28}, \mathrm{Trp}^{30}, \mathrm{Tr}^{32}, \mathrm{Ile}^{33}$, $\mathrm{Phe}^{43}, \mathrm{Ile}^{88}, \mathrm{Leu}^{101}$, and $\mathrm{Met}^{104}$ of the $\beta$-sheet region. The total hydrophobic interface between the subunits (defined as the surface area of carbon and sulfur atoms per subunit removed from solvent contact upon dimerization) was calculated to be $940 \AA^{2}$ versus the monomer surface area of $6400 \AA^{2}$ (23). This value corresponds to $19 \mathrm{kcal}$ $\mathrm{mol}^{-1}$ of stabilization energy per monomer when a conversion of $20 \mathrm{cal} \mathrm{mol}^{-1} \AA^{-2}$ is used (24-26).

There are two twofold-related solventaccessible cavities between the interchain disulfide bridge and the hydrophobic cores in the interface area. Four water molecules were observed in the electron density map to fill each void. It is not clear whether these voids and the accessible interchain disulfide bond have any functional role.

The TGF- $\beta$ superfamily includes cytokines that share at least $25 \%$ sequence identity with TGF- $\beta 1$ and that have seven invariant cysteines in the amino acid sequence of each chain. Of particular importance is the role of these invariant cysteines in the structure and function of this cytokine superfamily. As mentioned above, among the nine cysteines in the structure of TGF- $\beta 2$, eight are essentially not accessible to solvent. This result argues strongly that they are important mainly for structural reasons rather than for direct functional reasons. The two cysteines missing in some members are residues 7 and 16, which form a disulfide bond in the amino-terminal region of TGF- $\beta 2$, where homology with other members of the superfamily is weak. The other disulfides constitute a core structure that is complementary to the hydrogen bond network. As illustrated in Fig. 2B, there are extensive hydrogen bonds between fingers one and two, three, and four but few between the thumb and finger one, fingers two and three, and fingers one and four. Instead, these adjacent strands that are not extensively joined by hydrogen
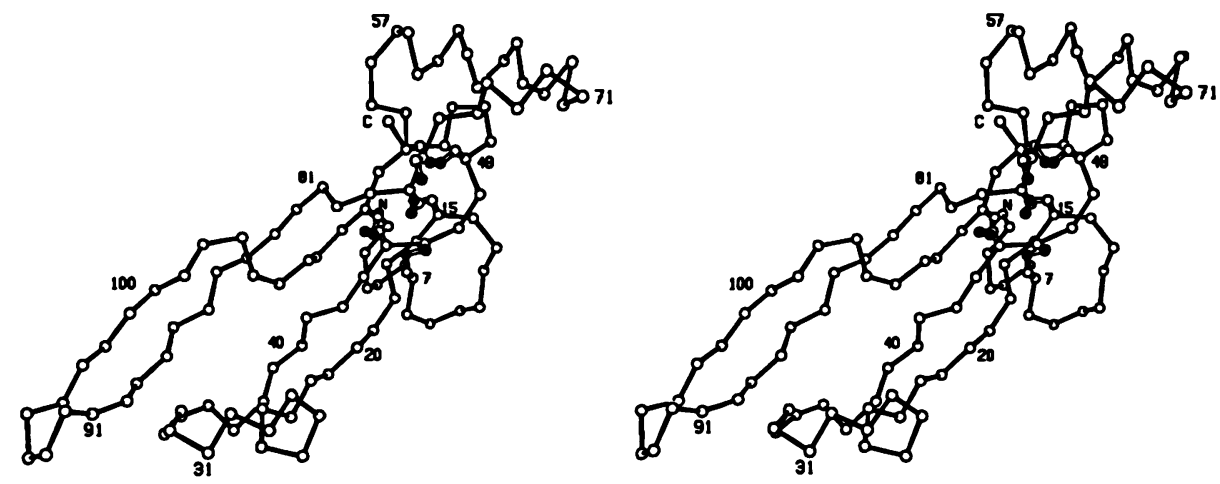

Fig. 3. ORTEP drawing of the $\mathrm{C} \alpha$ backbone (in stereo) of a TGF- $\beta 2$ subunit (42). Cysteine side chains (open bonds and solid spheres for sulfurs) are shown.

Table 1. Structure determination. Crystals were grown by vapor diffusion, by using standard hanging-drop methods (31). They belong to space group $P_{3} 21$ with cell dimensions $a=b=60 . \Phi$ $\AA$ and $c=75.3 \AA$. With one subunit of TGF- $\beta 2$ per asymmetric unit, the Matthew's volume, $V_{\mathrm{m}}$, is $3 . \bar{\delta}$ corresponding to a solvent content of $61 \%$. Both the native and derivative data were collected with a Siemens area detector mounted on a Rigaku rotating-anode $x$-ray generator and were processeep by using the program XDS $(32,33)$. Three derivatives were used. The major binding site of $\mathrm{UO}_{2} \mathrm{SO}_{4}^{-}$ was solved by using the Patterson vector search part of the program PROTEIN. The binding site of the iodine and mercury derivatives were solved by a cross-Fourier technique by using the majoE site of $\mathrm{UO}_{2} \mathrm{SO}_{4}$ as the phasing site. The heavy-atom parameters were refined by using the progran PHASIT (34). The initial phases were deduced from the multiple isomorphous replacement (MIR) by using the three heavy atom derivatives at $3.2 \AA$ resolution and the single anomalous scattering (SAS) of $\mathrm{UO}_{2} \mathrm{SO}_{4}$ at $3.5 \AA(35)$. The mean figure of merit was 0.68 . A slightly improved solvent-flattened map (36) was largely interpretable and allowed $70 \%$ of the sequence to be trace by using the graphic program (O) (37). A second electron density map was calculated at: $2.8 \AA$ resolution by using combined phases from the $3.2 \AA$ MIR, the $3.5 \AA$ SAS, and $2.8 \AA$ singl $\mathcal{B}^{\circ}$ isomorphous replacement of $\mathrm{UO}_{2} \mathrm{SO}_{4}$, and the partial model phases. This map allowed the entire amino acid sequence, except residues 91 to 96 , to be traced. The model was refined with the program package TNT by using all of the reflections between 15 and $2.1 \AA$ resolution for which $\delta$ $>2 \sigma(F)(38)$. The initial refinement included data to $2.8 \AA$ resolution (with the TNT solvent moded included) with positional parameters only. The resolution was subsequently increased to $2.4 \AA$ witto restrained crystallographic $B$ factors and to $2.1 \AA$ with individual isotropic $B$ factors. The final modef? has a crystallographic $R$ factor of 0.172 and consists of all 890 protein atoms, including both amin and carboxyl termini, and 32 solvent molecules. The density corresponding to residues 91 to 96 wass weak and ill-defined.

\begin{tabular}{|c|c|c|c|c|}
\hline Parameter & Native & $\mathrm{UO}_{2} \mathrm{SO}_{4}$ & $\mathrm{I}_{2}$ & $\mathrm{Hg}_{2} \mathrm{O}$ \\
\hline \multicolumn{5}{|l|}{ Diffraction data } \\
\hline Observations (no.) & 54,248 & 11,726 & 15,886 & 20,624 \\
\hline Unique reflections (no.) & 9,706 & 4,129 & 2,793 & 2,820 \\
\hline Resolution $(\AA)$ & 2.1 & 2.8 & 3.2 & 3.2 \\
\hline Completeness (\%) & 87 & 95 & 97 & 99 \\
\hline$R_{\text {sym }}{ }^{*}$ & 0.047 & 0.022 & 0.052 & 0.089 \\
\hline \multicolumn{5}{|l|}{ Phasing statistics } \\
\hline $\begin{array}{l}R_{\text {iso }}{ }^{-} \\
\text {Heavy atom sites }\end{array}$ & & $\begin{array}{l}0.14 \\
2\end{array}$ & $\begin{array}{l}0.136 \\
7\end{array}$ & $\begin{array}{l}0.10 \\
3\end{array}$ \\
\hline Isomorphous difference (no.) & & 3,994 & 2,737 & 2,722 \\
\hline Anomolous difference (no.) & & 1,652 & & \\
\hline$R_{\text {Cullis }} \neq$ & & 0.40 & 0.48 & 0.55 \\
\hline Phasing power§ & & 1.9 & 1.8 & 1.7 \\
\hline Mean figure of merit at $3.2 \AA$ & & 0.68 & & \\
\hline Mean figure of merit at $2.8 \AA$ & & 0.69 & & \\
\hline \multicolumn{5}{|l|}{ Refinement } \\
\hline Resolution $(\AA)$ & $15-2.1$ & & & \\
\hline Protein atoms & 890 & & & \\
\hline Water molecules & 32 & & & \\
\hline$R$ factor $\|$ & 0.172 & & & \\
\hline RMS bond length $(\AA)$ ฯ & 0.012 & & & \\
\hline RMS bond angle (degree) & 2.3 & & & \\
\hline RMS planar groups $(\AA)$ & 0.016 & & & \\
\hline
\end{tabular}

${ }^{*} R_{\text {sym }}=\Sigma_{h} \Sigma_{i} \mid(h)_{i}-\langle/(h)\rangle / \Sigma_{h} \Sigma_{i} /(h)_{i} l(h)$ is the intensity of reflection $h, \Sigma_{h}$, sum over all reflections, and $\Sigma_{i,}$ sum ${ }^{2} R_{\text {sym }}=\Sigma_{h} \Sigma_{i} /(h)_{i}-\langle(h)\rangle / \Sigma_{h} \Sigma_{i} /(h)_{i}$
over the $i$ th measurement. $+R_{i s o}=\Sigma_{h}\left|F_{\mathrm{PH}}-F_{\mathrm{P}}\right| / \Sigma_{h} F_{\mathrm{P}} ; F_{\mathrm{P}}$ and $F_{\mathrm{PH}}$ are the native and derivative structure factor amplitudes, respectively. $\quad \neq R_{\text {Cullis }}=\Sigma_{h} \mid F_{\mathrm{H}}$ (obs) $-F_{\mathrm{H}}$ (calc) $\mid / \Sigma_{\mathbf{h}} F_{\mathrm{H}}$ (obs), $F_{\mathrm{H}}$ is the heavy atom structure factor amplitude. \$Phasing power $=F_{\mathrm{H}}(\mathrm{calc}) / E$ or $2 F_{\mathrm{H}}{ }^{\prime \prime}$ (calc) $/ E$, for isomorphous and anomalous differences, respectively. $E$ is the estimated error. $\| R$ factor $=\Sigma_{\mathbf{h}} \mid F($ obs $)-F\left(\right.$ calc) $\mid / \Sigma_{\mathbf{h}} F($ obs $)$. IRMS, root-mean-square. 
Flg. 4. Ribbon drawing of a dimer of TGF- $\beta 2$. The two subunits are colored yellow and blue. Shown in white are the cysteine side chains and disulfide bonds. The residues shown in yellow and blue are the hydrophobic residues that form the interface between the two subunits. The twofold axis is at the interchain disulfide bond and perpendicular to the page. The drawing was made with the program Ribbons (43).

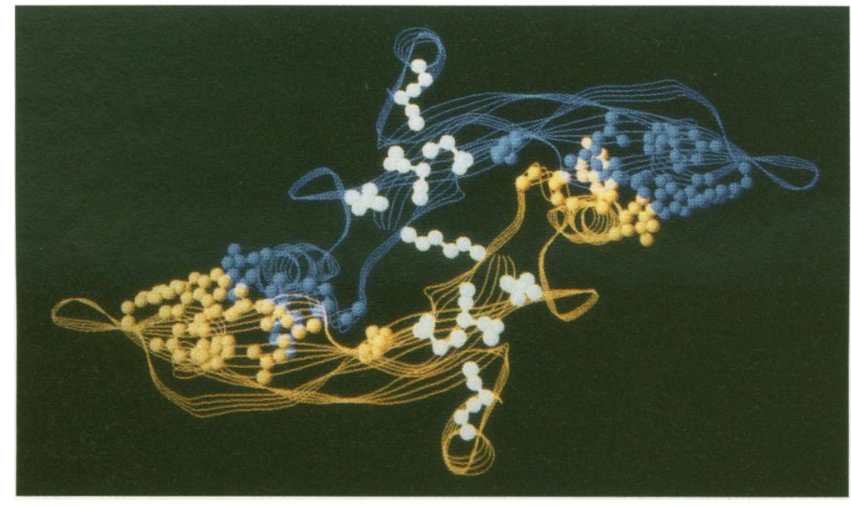

Table 2. Sequence comparisons and $3-D-1-D$ profile scores for the TGF- $\beta$ superfamily. The sequences were first aligned by the GCG program package (39). A penalty of -0.1 was applied if a gap or an insertion was in a loop region and -1.0 if it was in an $\alpha$ helix or a $\beta$ sheet. Included as controls are the variable domains of two mouse immunoglobulin light chains, J539 and McPC603, which are known to have similar structures by $x$-ray diffraction $(40,41)$. The $Z$ scores indicate similarity among TGF- $\beta 2$ and other TGF- $\beta$ family members.

\begin{tabular}{|c|c|c|c|c|}
\hline Sequence & Source & Length & $Z$ & $\begin{array}{c}\text { Sequence } \\
\text { identity } \\
\text { (\%) }\end{array}$ \\
\hline \multicolumn{5}{|l|}{ TGF- $\boldsymbol{\beta} 1$ to $5^{*}$} \\
\hline TGF-B2 & Human & 112 & 50.5 & 100 \\
\hline TGF- $\beta 1$ & Human & 112 & 48.5 & 72 \\
\hline TGF- $\beta 3$ & Human & 112 & 47.6 & 80 \\
\hline TGF- $\beta 4$ & Chicken & 114 & 51.9 & 66 \\
\hline TGF- $\beta 5$ & $X$. laevis & 112 & 49.8 & 66 \\
\hline \multicolumn{5}{|c|}{ TGF- $\beta$ superfamily* } \\
\hline Inhibin $\beta A$ & Human & 112 & 21.2 & 39 \\
\hline Inhibin $\beta B$ & Human & 111 & 16.7 & 35 \\
\hline BMP 2 & Human & 100 & 21.0 & 34 \\
\hline BMP 4 & Human & 104 & 19.6 & 35 \\
\hline Vg1 & $X$. laevis & 109 & 23.7 & 36 \\
\hline DPP-C & Drosophila & 102 & 20.8 & 36 \\
\hline MIS & Human & 107 & 12.2 & 23 \\
\hline Inhibin $\alpha$ & Human & 113 & 6.5 & 26 \\
\hline \multicolumn{5}{|c|}{ Immunoglobulin VL† } \\
\hline J539 & Mouse & 107 & 44.6 & 100 \\
\hline МсРС603 & Mouse & 114 & 27.9 & 55 \\
\hline
\end{tabular}

*The profile deriving sequence is TGF- $\beta 2$ and the sequence identity is calculated between $\beta 2$ and each of the superfamily members. tThe profile deriving sequence is $\mathrm{J} 539$. The structure and sequence of the antibody $\mathrm{J} 539$ is obtained from the Brookhaven Data Bank entry 2FBJ and the sequence of McPC603 is obtained from Brookhaven Data Bank entry 1MCP. In both $\mathrm{J} 539$ and McPC603 cases, only the light chains of the variable domain are compared.

bonds are linked by disulfides. This core structure (the palm of the hand) can be expected to be common to all of the members of the TGF- $\beta$ superfamily. The aminoterminal domain, the heel of the hand, and the design of the fingers can be expected to be variable features of the backbone structure among superfamily members.

The members of the superfamily can be further divided into subfamilies, for example, TGF- $\beta 1$ through $-\beta 5$, within which there is much greater sequence identity. Model building has shown that the TGF- $\beta 1$ sequence can be fit to the TGF- $\beta 2$ backbone without significant distortion of the backbone coordinates. All of the differences are in surface residues, except for residue 58 , which is in the hydrophobic interface (His in TGF- $\beta 2$ and Tyr in TGF- $\beta 1)$, strongly suggesting that the differences in biological activity between these two family members depend on differences in surface side chains rather than in tertiary structure.

A method has recently been proposed that scores the compatibility of amino acid sequences with a known 3-D structure (20, 21). We have applied this method to compare the sequences of the proteins in the TGF- $\beta$ superfamily and scored the compatibility of each individual sequence to the 3 -D profile generated from the structure of TGF- $\beta 2$ (Table 2).

TGF- $\beta 1$ through $-\beta 5$ have similar profile scores ( $Z$ score), implying similar 3-D structures, which is not surprising since there is $\sim 70 \%$ sequence identity among them. The other members of the superfamily share 25 to $40 \%$ sequence identity with TGF- $\beta 2$ (Table 2). The profile analysis shows that most of these proteins cluster with $Z$ values near 20 except for MIS and inhibin $\alpha$ chain, which have lower scores than the rest. This result indicates a close structural similarity between the superfamily members and TGF- $\beta 2$.

The 3-D structure of TGF- $\beta 2$, as described here, should provide a rational basis for understanding structure and function of this important cytokine and other members of the family. Of particular importance is binding of these cytokines to cell-surface receptors. Several receptors present on most cells have been identified [see (2)], and two have been cloned $(27,28)$. Different affinity constants have been observed for TGF- $\beta 1$ and $-\beta 2$. Recently, receptors that are less ubiquitous but very selective for TGF- $\beta 1$ or $-\beta 2$ have been reported $\stackrel{\curvearrowright}{N}$ (29).

Recent studies of a chimeric TGF- $\beta 1 \stackrel{\infty}{-}$ and $-\beta 2$ have shown that differences in $\bar{\otimes}$ specificity can be associated with residues 40 to 82 (30). Of the 42 residues, 14 differ between TGF- $\beta 1$ and $-\beta 2$ and thus must be $\frac{O}{Z}$ responsible for the differences in specific activity mediated by receptors in the endo- 0 thelial cell growth inhibition assay used. Examination of the structure of TGF- $\beta 2$ reveals that these residues are mostly located in the heel of the subunit (Fig. 2A). All but one $\left(\mathrm{His}^{58}\right.$ to $\left.\mathrm{Tyr}\right)$ are surface residues. Furthermore, they form a surface patch $\frac{\mathscr{O}}{\mathrm{O}}$ consisting of residues from both subunits in this region of the molecule. It is therefore conceivable that this patch participates in the interaction with receptors. Although $E$ the exact binding site is yet to be defined, the structure of TGF- $\beta 2$ provides a frame- $D$ work upon which further studies of structure-function relations can be based.

\section{REFERENCES AND NOTES}

1. M. B. Sporn and A. B. Roberts, in Peptide Growth Factors and Their Receptors I, M. B. Sporn and A. B. Roberts, Eds. (Springer-Verlag, New York, 1990), chap. 8.

2. J. Massagué, Annu. Rev. Cell Biol. 6, 597 (1990).

3. K. A. Piez and M. B. Sporn, Eds., Transforming Growth Factor- $\beta$ s. Chemistry, Biology and Therapeutics, Ann. N.Y. Acad. Sci. 593 (1990).

4. R. M. Lyons and H. L. Moses, Eur. J. Biochem. 187, 467 (1990)

5. M. B. Sporn and A. B. Roberts, Cell Regul. 1, 875 (1990).

6. C. A. Frolik, L. L. Dart C. A. Meyers, D. M. Smith, M. B. Sporn, Proc. Natl. Acad. Sci. U.S.A. 80 , 3676 (1983)

7. R. K. Assoian, A. Komoriya, C. A. Meyers, D. M. Miller, M. B. Sporn, J. Biol. Chem. 258, 7155 (1983)

8. A. B. Roberts et al., Biochemistry 22, 5692 (1983).

9. S. M. Seyedin et al., J. Biol. Chem. 262, 1946 (1987).

10. S. Cheifetz et al., Cell 48, 409 (1987)

11. M. Wrann et al., EMBO J. 6, 1633 (1987).

12. S. K. Hanks et al., Proc. Natl. Acad. Sci. U.S.A. 85 , 79 (1988)

13. P. ten Dijke, P. Hanson, K. K. Iwata, C. Pieler, 
J. G. Foulkes, ibid., p. 4715

14. R. Derynck et al., EMBO J. 7, 3737 (1988)

15. S. B. Jakowlew, P. J. Dillard, P. Kondaiah, M. B. Sporn, A. B. Roberts, Mol. Endocrinol. 2, 747 (1988).

16. S. B. Jakowlew, P. J. Dillard, M. B. Sporn, A. B. Roberts, ibid., p. 1186.

17. P. Kondaiah et al., J. Biol. Chem. 265, 1089 (1990).

18. Y. Ogawa, D. K. Schmidt, J. R. Dasch, R.-J. Chang, C. B. Glaser, ibid. 267, 2325 (1992).

19. Y. Ogawa, personal communication.

20. J. U. Bowie, R. Lüthy, D. Eisenberg, Science 253, 164 (1991).

21. R. Lüthy, J. U. Bowie, D. Eisenberg, Nature 356 83 (1992).

22. S. Archer and D. Torchia, personal communication

23. T. J. Richmond and F. M. Richards, J. Mol. Biol. 119, 537 (1978)

24. C. Chothia, Nature 248, 338 (1974).

25. M. Matsumura, W. J. Becktel, B. W. Matthews ibid. 334, 406 (1988)

26. A. E. Eriksson et al., Science 255, 178 (1992)

27. X.-F. Wang et al., Cell 67, 797 (1991)

28. F. Lopez-Casillas et al., ibid., p. 785.

29. S. Cheifetz and J. Massagué, J. Biol. Chem. 266 20767 (1991)

30. S. W. Qian et al., Proc. Natl. Acad. Sci. U.S.A., in press.

31. Purified mature TGF- $\beta 2$, a recombinant form expressed in mammalian cells, was provided by Celtrix Pharmaceuticals, Inc. (Santa Clara, CA). The protein was supplied at $40 \mathrm{mg} / \mathrm{ml}$ in $0.1 \%$ trifluoroacetic acid $40 \%$ acetonitrile, and was diluted four times with $10 \mathrm{mM}$ acetate buffer $\mathrm{pH}$ 4.0. Crystals were grown from $10-\mu l$ drops consisting of equal parts of the diluted protein solution and well solvent. The well solvent contained $20 \%$ PEG 200, $50 \mathrm{mM}$ sodium acetate buffer at $\mathrm{pH}$ 4.2 and 30 to $50 \mathrm{mM}$ unbuffered sodium acetate added as precipitant. Typical crystals, measuring $0.5 \mathrm{~mm}$ by $0.5 \mathrm{~mm}$ by $0.3 \mathrm{~mm}$, grew in about 10 days and diffracted to better than $2.0 \AA$. Crystals were stabilized with 10\% PEG 200, $50 \mathrm{mM}$ buff-

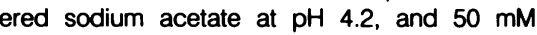
unbuffered sodium acetate prior to data collection.

32. W. Kabsch, J. Appl. Crystallogr. 21, 67 (1988).

33. , ibid., p. 916

34. The program package PHASIT was written and kindly provided by W. Furey.

35. W. A. Hendrickson and E. E. Lattman, Acta Crystallogr. B26, 136 (1970)

36. B.-C. Wang, Methods Enzymol. 115, 90 (1985)

37. T. A. Jones, J.-Y. Zou, S. W. Cowan, Acta Crystallogr. A47, 110 (1991).

38. D. E. Tronrud, L. F. Ten Eyck, B. W. Matthews, ibid. A34, 489 (1987).

39. The sequence analysis program package GCG is the product of Genetics Computer Group, University of Wisconsin Biotechnology Center.

40. Y. Satow, G. H. Cohen, E. A. Padlan, D. R. Davies, J. Mol. Biol. 190, 593 (1986).

41. T. N. Bhat, E. A. Padlan, D. R. Davies, Brookhaven Protein Data Bank entry 2FBJ.

42. C. K. Johnson, ORTEP: A Fortran Thermal-Ellipsoid Plot Program For Crystal Structure Illustrations (Oak Ridge National Laboratory, Oak Ridge, TN, 1970)

43. M. Carson, J. Mol. Graphics 5, 103 (1987)

44. We thank $D$. Eisenberg for kindly providing the 3-D-1-D profile analysis programs and D. Torchia and M. B. Sporn for access to their unpublished results. Part of this work was done while K.A.P. was a Scholar-in-Residence at the Fogarty International Center, National Institutes of Health. The refined coordinates are being deposited in the Brookhaven Protein Data Bank.

22 May 1992; accepted 24 June 1992

\section{Ocean Warming and Sea Level Rise Along the Southwest U.S. Coast}

\section{Dean Roemmich}

Hydrographic time-series data recorded during the past 42 years in the upper 500 meters off the coast of southern California indicate that temperatures have increased by $0.8^{\circ} \mathrm{C}$ uniformly in the upper 100 meters and that temperatures have risen significantly to depths of about $\mathbf{3 0 0}$ meters. The effect of warming the surface layer of the ocean and thereby expanding the water column has been to raise sea level by $0.9 \pm 0.2$ millimeter per year. Tide gauge records along the coast are coherent with steric height and show upward trends in sea level that vary from about 1 to 3 millimeters per year.

Global sea level appears to be rising at a rate of about $2 \mathrm{~mm} /$ year $(1,2)$. A variety of factors may contribute to sea level rise (3), including steric expansion of the water as a result of warming, an increase in the mass of water in the oceans as a result of glacial melting, and changes in the shape and volume of the ocean basins. A major step toward predicting future sea level rise and the impact of human activity on sea level is to distinguish the individual factors affecting the present sea level record. Moreover, if sea level rise is indicative of ocean warming, it is critical to determine the vertical

Marine Life Research Group, Scripps Institution of Oceanography, La Jolla, CA 92093. distribution of the temperature change. The extent to which warming is concentrated in the surface layer must influence the ultimate impact of climate change on marine life. In this paper, I describe a study of long-term upper-ocean steric change with the use of a comprehensive regional hydrographic time series off California. The study focuses on the distribution of changes in steric height over position, depth, and time, and the relation of these changes to coastal sea level.

Repeated hydrographic and biological sampling along the California coast was initiated in 1950 and continues to the present. Stations in the sampling grid (Fig. 1) are typically 30 to $60 \mathrm{~km}$ apart, and the coverage at each station extends to depths of about $500 \mathrm{~m}$ in water up to $4 \mathrm{~km}$ deep. This survey, the California Cooperative Oceanic Fisheries Investigations (CalCOFI), has been carried out jointly by the state of California, the Scripps Institution of Oceanography, and the National Marine Fisheries Service. During the 1950s CalCOFI cruises were conducted up to ten times per year and coverage was extensive from Oregon to Baja California. The survey has been redefined several times. A serious hiatus in temporal resolution occurred during the 1970s, with only five cruises off southern California from 1969 to 1976. From 1984 to the present, sampling has been carried out quarterly along the six lines from San Diego to Point Conception (Fig. 1). I focus on this region.

CalCOFI Line 90 (Fig. 1) is the mo heavily sampled of all the lines, with 1 की repetitions. For each transect along Line 90 , I interpolated the temperature and salinity data onto an evenly spaced grid witw the use of an objective mapping procedure (4). I removed seasonal cycles indeper dently at each grid point by subtracting the difference between the average over at cruises during a given month and the aves age over the 12 months. Nonseasonal resi⿺ uals showed warming of nearly $1^{\circ} \mathrm{C}$ in th upper $100 \mathrm{~m}$ at all stations; at some statios warming was evident to depths of $300 \mathrm{~m}$ more.

In order to help suppress sampling noise data from each cruise were averaged hot zontally over the highly sampled intervis from station 90.35 (50 km offshore) to 90.70 (315 km offshore). For this intervat the vertically integrated effect of the ter perature and salinity changes on the heig of the sea surface is shown in a time series steric height (5) (Fig. 1). Large positif offsets that occurred during the major Niño episodes of 1957 to 1958 and 1982 1983 are notable in the steric height record. Steric height subsequently decreased after each episode but never fully returned to the pre-El Niño values. The trend in steric height from 1950 to the present shown in Fig. 1 amounts to $0.9 \pm 0.2 \mathrm{~mm} /$ year. This trend is due to temperature change (Fig. 2B), with no substantial contribution from salinity. Line 93 off San Diego and Line 80 near Point Conception were also well sampled during the 42-year interval (138 and 132 transects); the results from these lines are similar to those from Line 90.

Net changes over the total length of the record are illustrated by averaging over the initial and final 7-year periods, from 1950 to 1956 and 1985 to mid-1991. These two intervals contained no major El Niño episodes. The steric height increase (Fig. 2A) was nearly $3 \mathrm{~cm}$ and, within the statistical uncertainty of the estimates, was spatially 